\title{
Supersonic Technology Concept Aeroplanes for Environmental Studies
}

\author{
Jeffrey J. Berton, ${ }^{*}$ Dennis L. Huff, ${ }^{\dagger}$ and Jonathan A. Seidel ${ }^{*}$ \\ NASA Glenn Research Center, Cleveland, Ohio 44135 \\ Karl A. Geiselhart ${ }^{\S}$ \\ NASA Langley Research Center, Hampton, Virginia 23681
}

\begin{abstract}
The International Civil Aviation Organization is considering new environmental standards for future supersonic civil aircraft. NASA is supporting this effort by analyzing several notional, near-term supersonic transports. NASA's performance, noise, and exhaust emission predictions for these transports are being used to inform a larger study that will determine the global environmental and economic impact of adding supersonic aircraft to the fleet beginning this decade. A supersonic business jet with a maximum takeoff gross weight of 55 tonnes is the focus of this paper. A smaller business jet weighing 45 tonnes is also discussed. Both airplanes use supersonic engines derived from a common contemporary commercial subsonic turbofan core. Aircraft performance, airport-vicinity noise, and exhaust emissions are predicted using NASA tools. Also investigated are some of the anticipated behaviors and requirements of these aircraft in the commercial airspace. The sensitivity of noise to system uncertainties is presented and alternative engine studies are discussed.
\end{abstract}

\section{Introduction}

SUPERSONIC Technology Concept Aeroplanes are notional research vehicles studied with the intent to provide Sinformation to the International Civil Aviation Organization by way of their Committee on Aviation Environmental Protection. Though several STCAs are currently being investigated by CAEP, the focus of this paper is the analysis of an eight-passenger, 55t (121klb) trijet. A smaller $45 \mathrm{t}(100 \mathrm{klb})$ twinjet is also discussed. Information for the $55 t$ trijet is publically available, while much of the information for the $45 t$ twinjet is restricted. Both airplanes** are intended to be generally representative of early market entrant supersonic business jet aircraft currently under development by industry. They are designed to travel transatlantic distances at Mach 1.4 using relatively near-term technologies. Each airplane is equipped with notional engines that are designed and assessed by NASA. They are derived from the core of a contemporary, "off-the-shelf" subsonic turbofan.

The 55t trijet is designed wholly by NASA. All aspects of the airplane and engine have been developed entirely with information from the public domain. Being nonproprietary and transparent, the 55t airplane is ideal for use in ICAO's public studies. Aircraft mission performance, airport-vicinity noise, and exhaust emissions are predicted for the $55 \mathrm{t}$ transport using NASA tools. The $55 \mathrm{t}$ airplane is emphasized in this paper. It is a continuation of work described earlier in Ref. [1].

There are three motivations for this study. First, during the eleventh triennial cycle of CAEP, subgroups were formed in 2016 by the rapporteurs of CAEP's noise and exhaust emissions working groups. The charter of these subgroups is to examine the suitability of existing noise and exhaust emission certification standards for new supersonic civil airplane types. The subgroups are tasked with developing appropriate standards and recommended practices to support anticipated entries of new supersonic civil transports. The ultimate goal of both subgroups is to recommend amendments to Part II, Chapter 12 of [2] and to Part III, Chapter 3 of [3] that more properly address noise and exhaust emissions of supersonic airplane types, respectively. Both subgroups are dedicated to ensuring that new

\footnotetext{
*Aerospace Engineer, Propulsion Systems Analysis Branch, senior member AIAA.

${ }^{\dagger}$ Aerospace Engineer, Acoustics Branch, associate fellow AIAA.

*Aerospace Engineer, Propulsion Systems Analysis Branch.

${ }^{\S}$ Aerospace Engineer, Aeronautics Systems Analysis Branch.

** In referring to STCAs, "aeroplane" is the spelling used by ICAO. The spelling "airplane," however, is used in this paper.
} 
supersonic transports operate responsibly in an environmentally sustainable manner. NASA is assisting these subgroups by acting as analysts and independent arbitrators and by providing unbiased, open assessments of supersonic civil aircraft.

Second, the Federal Aviation Administration Reauthorization Act of 2018 [4] requires the FAA to "exercise leadership in the creation of Federal and international policies, regulations, and standards relating to the certification and safe and efficient operation of civil supersonic aircraft." More specifically, it requires the FAA to issue a notice of proposed rulemaking regarding landing and takeoff noise standards for supersonic aircraft by 31 March 2020. The FAA's intention is to revise its noise standards [5] to include provisions for future supersonic transports. NASA is assisting the FAA in this effort.

Third, at CAEP's eleventh triennial meeting in February, 2019, the committee agreed to conduct an exploratory study on the global impact of future civil supersonic aircraft. This exploratory study is part of the work program of CAEP's twelfth (current) cycle. The study will predict the outcome of analytically adding supersonic transports to the existing civil aircraft fleet. The influence that supersonic airplanes will have on operations, fuel consumption, airport noise, and air quality will be assessed. The FAA has requested NASA to help assess these impacts by providing vehicle performance, fuel burn, noise, and exhaust emission data of the 55t STCA to support the study. The 55t STCA is an analytical proxy for future supersonic airplane types. CAEP is using the Aviation Environmental Design Tool (AEDT) $[6,7]$ to assess the impacts. Aircraft noise and performance (ANP) data [8] and exhaust emissions data in the form of [9] for the 55t STCA are required to support the exploratory study. These are documented in this paper.

Presented in this paper is a description of the STCA's propulsion and airframe analysis, predictions of takeoff and landing profiles and procedures, mission performance, and predictions of noise and exhaust emissions. Also investigated are some of the anticipated behaviors and requirements of these aircraft in the commercial airspace. A sensitivity analysis of certification noise to system uncertainties is presented, and alternative engines are discussed.

In a related effort, simulated audio recordings of the 55t STCA taking off are created using a process by which numerical noise predictions are converted into sounds that can be heard [10]. Such "auralizations" are helpful in communicating the impact of takeoff procedures to those who are not acousticians. A companion paper describing this effort has been written [11].

\section{Engine and Airframe}

\section{A. Propulsion}

For an early market entrant, it is unlikely that a completely new engine could be developed and be ready in time for a near-term entry into service. Instead, it is more likely that the low-pressure spool of a contemporary off-the-shelf engine would be redesigned, resulting in a supersonic variant of an existing subsonic turbofan. In this study, an analytical model of a subsonic CFM56-7B27 is used as the "donor" engine from which the supersonic engine is derived. Interestingly, the original CFM56-2, granted certification in 1979, was itself derived from the GE F101 and 102 models used for the supersonic B-1A bomber. Redesigning the low-pressure spool of a CFM56 once again for a supersonic application would bring the engine family full circle.

Because much engine design data are closely-held, proprietary, and unavailable, any analytic simulation of a CFM56 (outside of CFM International) will necessarily have some inherent inaccuracy. Nevertheless, if data can be obtained from public-domain sources (such as type certificate data sheets, manufacturer-provided operating documents, technical reports, and manufacturer's websites), simulations of turbofans developed outside of engine companies can be reasonably accurate. A model of the subsonic CFM56 is created with such information using the Numerical Propulsion System Simulation code (NPSS, $[12,13])$ to predict engine performance. NPSS is an engine cycle analysis tool developed jointly by NASA and by United States aerospace industry. It is currently the accepted, state-of-the-art software for airbreathing engine cycle performance analysis for United States industry, academia, and NASA. The subsonic CFM56 model is adapted from work performed under the FAA's Environmental Design Space initiative [14].

The low-pressure spool of the CFM56-7B is redesigned for a Mach 1.4 cruise application. The booster is discarded (with it, supersonic ram effects would elevate aft stages of the compressor to excessive temperature), and the fan and low-pressure turbine are redesigned for a higher pressure ratio. Fan performance is modeled using data collected at NASA from the GE57 scale model fan [15]. The GE57 fan is considered to be perhaps representative of what might be used by an engine manufacturer in a supersonic refan application. It consists of a single stage and operates at peak efficiency at a pressure ratio of 2.2. Fan pressure ratio is a design variable strongly influencing engine performance. A high fan pressure ratio is preferred to create an exhaust velocity high enough for supersonic flight, while a low fan pressure ratio is required to meet takeoff and landing noise requirements. Fan pressure ratio, along with a practical

2 of 19

American Institute of Aeronautics and Astronautics 
extraction ratio, directly determine the bypass ratio of the engine. This poses conflicting requirements for supersonic engine designers. If fan pressure ratios are high enough, they could lead to supercritical nozzle pressure ratios at low altitude and create high levels of jet shock cell noise during takeoff.

Another design choice is whether to forcibly mix the core and bypass streams or to allow them to remain separate. There are compelling reasons to mix the streams. There is usually an increase in gross thrust when flows are forcibly mixed and exhausted through a common nozzle, with the benefit increasing with increasing core stream temperature. Although the benefit is slight, it can be important to net thrust at high speed when ram drag is high. And the outer mold lines of a simpler, single-stream nozzle are preferred over those of a more complex coannular nozzle if sonic boom reduction is important. In this study, core and bypass streams are forcibly mixed through a lobed mixer. The design extraction ratio is kept near unity so that mixer bypass port and mixer exit Mach numbers are always manageable and less than 0.5 .

The mixed flow exits through a single-stream convergent-divergent plug nozzle. The centerbody plug and nozzle throat are fixed while the divergent flaps are variable. The plug is important in keeping aftbody boattail angles small during supersonic cruise while also lowering takeoff jet noise slightly. At low altitudes, the divergent nozzle flaps are closed to a minimum area so that the nozzle exit plane is the throat. Solid models of the CFM567B and the derived supersonic variant are shown in Figure 1. Not shown in the Figure are the nozzles or inlets for either engine.

At the cycle design point, characteristics of the compressor and the high-pressure turbine are set manually to those of the CFM56 donor engine. This keeps the highpressure spool of the supersonic derivative engine identical to the CFM56 core. Bleed flow fractions and core flow passage areas are also held constant. Hot section temperatures are kept nearly as high as the CFM56

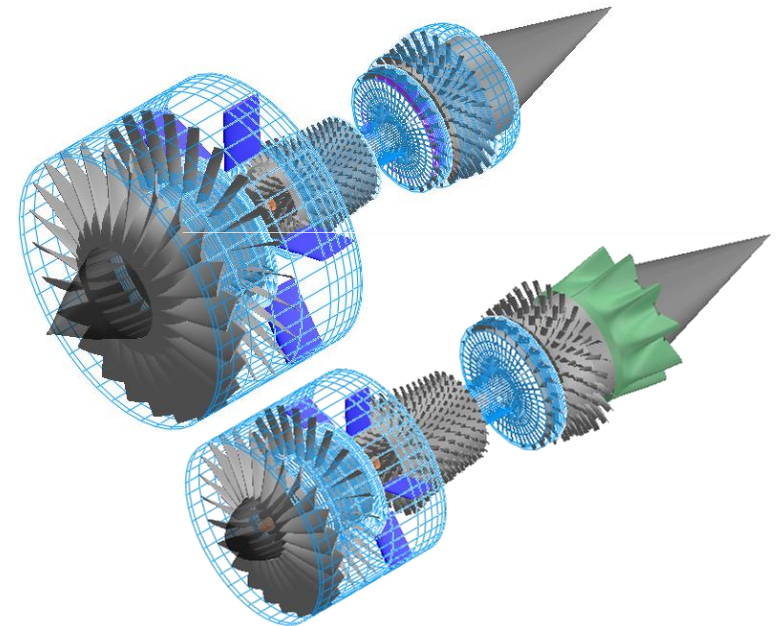

Figure 1. Solid models of the CFM56-7B (top) and notional modified supersonic variant (bottom). maximum takeoff temperatures. But since the supersonic variant would spend several hours at maximum temperature (compared to just a few minutes during takeoff for a subsonic turbofan), this becomes a rather important assumption. Maintaining high temperatures is justified by assuming increased hot section overhaul frequency (not uncommon for a business jet application), and perhaps by offering new turbine airfoils with improved materials, coatings, and better cooling effectiveness.

Fan pressure ratios are selected such that the nozzle operates on the cusp of choke near sea level. With a small amount of engine derating at low altitude (the logic of engine derating is discussed in a later section), jet shock cell noise is eliminated during takeoff. A summary of engine performance data is shown in Table 1. Ambient conditions above 10,000 feet use International Standard Atmosphere (ISA) conditions, while conditions nearer sea level use hot day $\left(\mathrm{ISA}+27^{\circ} \mathrm{F}\right)$ conditions. Performance data at sea level are shown after engine derating.

Table 1. Performance summary for the $55 \mathrm{t}$ trijet engine.

\begin{tabular}{l|c|c|c}
\hline \hline & $\begin{array}{c}\text { M1.4, 50kft, } \\
\text { ISA }\end{array}$ & $\begin{array}{c}\text { M0.25, sea } \\
\text { level, ISA+27 } \mathbf{~}^{\circ} \mathbf{F}\end{array}$ & $\begin{array}{c}\text { Sea level static, } \\
\text { ISA+27 }^{\circ} \mathbf{F}\end{array}$ \\
\hline \hline Net thrust, lb/engine & 3330 & 14,140 & 16,620 \\
Specific fuel consumption, $\mathrm{lb} / \mathrm{hr} / \mathrm{lb}$ & 0.943 & 0.588 & 0.479 \\
Bypass ratio & 2.9 & 2.9 & 3.0 \\
Burner temperature, ${ }^{\circ} \mathrm{R}$ & 3300 & 3150 & 3130 \\
${\text { Turbine inlet temperature, }{ }^{\circ} \mathrm{R}}^{\text {Compressor exit temperature, }{ }^{\circ} \mathrm{R}}$ & 3180 & 3040 & 3020 \\
Overall pressure ratio & 1450 & 1440 & 1430 \\
Fan pressure ratio & 22 & 21 & 21 \\
Compressor pressure ratio & 2.0 & 1.9 & 1.9 \\
Extraction ratio & 11.2 & 11.1 & 11.2 \\
Nozzle pressure ratio & 1.1 & 1.1 & 1.1 \\
\hline \hline
\end{tabular}

3 of 19

American Institute of Aeronautics and Astronautics 
Though the supersonic engine variant may appear similar to GE Aviation's Affinity ${ }^{\mathrm{TM}}$ engine [16] intended for Aerion Supersonic's proposed supersonic business jet, it is based on a NASA model predating Aerion Corporation's public partnership announcement with GE Aviation in 2018. It uses no company-proprietary information.

\section{B. 55t Concept Airframe}

The 55t STCA is a notional, eight-passenger business jet designed for Mach 1.4 supersonic overwater cruise speeds. It has a low-aspect ratio cranked delta wing. Three engines are mounted aft; the outboard engines are mounted on short fuselage pylons, while the center engine is integrated with the vertical tail. A summary of vehicle characteristics is shown in Table 2. A solid model of the airplane is shown in Figure 2.

The 55t airplane in this study has no features that would reduce its sonic boom noise signature, making it similar in that respect to other early market entrant designs. Supersonic speeds over land would be restricted where prohibited. Despite NASA's current interest in low-boom supersonic aircraft [17], those types of designs are viewed here as prospects for later market entrants.

Table 2: 55t trijet characteristics.

\begin{tabular}{l|c}
\hline \hline Max takeoff weight, klb & 121 \\
Passengers & 8 \\
Cruise Mach & 1.4 \\
Engines (x3) & CFM56-derived \\
Overall length, $\mathrm{ft}$ & 135 \\
Span, ft & 67 \\
Wing reference area, $\mathrm{ft}^{2}$ & 1619 \\
Wing aspect ratio & 2.7 \\
Wing taper ratio & 0.09 \\
Wing loading, lb/ft ${ }^{2}$ & 74 \\
Wing fuel, klb & 24 \\
Fuselage fuel, klb & 36 \\
Fuel fraction & 0.50 \\
\hline \hline
\end{tabular}

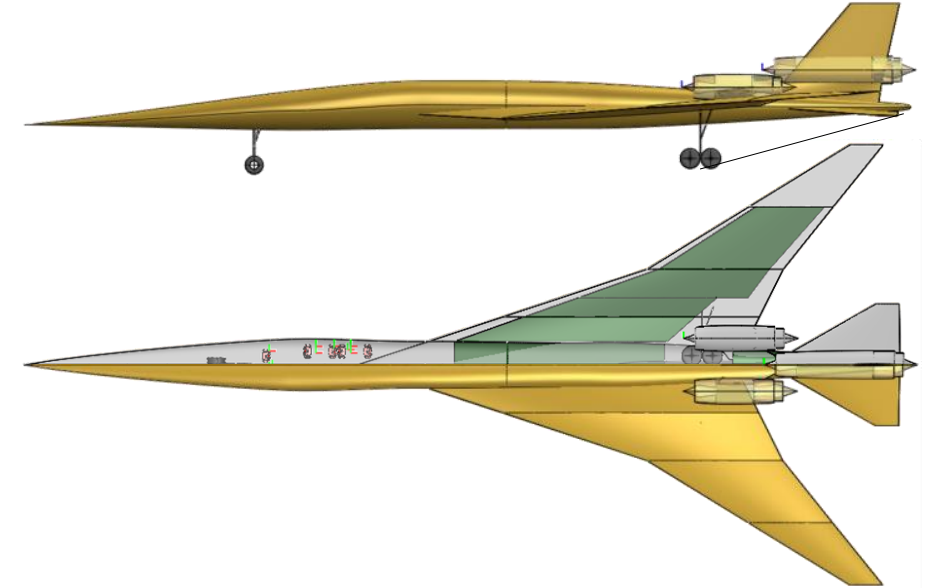

Figure 2. Solid model of the $55 t$ trijet concept.

Several aircraft conceptual design tools are used to synthesize the notional vehicle. A solid modeling tool [18] is used to define the outer mold lines of the airplane, to guide interior packaging, and to estimate internal fuel volume. The solid model also informs component weight and vehicle aerodynamic analyses. Lift-dependent drags, liftindependent drags, and wave drags are calculated by the methods described in Refs. [19], [20], and [21]. A weight estimate of the wing is made using physics-based factors based on its gross geometry, while weight estimates of other major structures and systems are made using statistical-empirical relations. All airframe weight estimation methods are discussed in [22]. These computer codes are organized together using a frameworking tool [23] which provides a conceptual-level, multidisciplinary, integrated process for designing and analyzing supersonic aircraft [24]. Using this integrated design environment, major aircraft design variables can be rapidly assessed and optimized. A design and sizing analysis of wing, fuselage and tail characteristics is performed, subject to practical performance constraints.

The vehicle design is optimized to maximize range for a fixed maximum gross weight of $55 \mathrm{t}(121 \mathrm{klb})$. Subject to a minimum cabin width of $7 \mathrm{ft}$, fuselage section height, width, and tangent angles at three stations are optimized to minimize wave drag. Wing planform shape, airfoil twist, and camber are varied to minimize wave drag and drag due to lift. Horizontal tail size and location, main gear location, and trailing edge and leading edge flap deflections are optimized to meet takeoff, landing, and cruise static margin constraints, and to ensure reasonable takeoff and landing field lengths and approach velocity.

\section{Aircraft Performance}

\section{A. Mission Performance}

With aerodynamics, engine thrust and fuel consumption performance known, a mission analysis of the transport can be made using NASA mission performance software [25]. The design mission is at maximum takeoff gross weight, non-stop, with a single cruise segment at supersonic speed. There are no subsonic cruise segments which might be typical of other missions where supersonic flight might be restricted. Since high-altitude air traffic should be light, the 
airplane is allowed to climb continuously during supersonic cruise for maximum range. The design mission uses the full payload complement of eight passengers. The mission rules described in [26] are followed, except that the five percent block fuel reserve allowance is omitted, which is more typical of mission rules followed by business jets. The mission profile is shown in Figure 3.

Table 3: $55 \mathrm{t}$ trijet performance.

\begin{tabular}{l|c}
\hline \hline Takeoff gross wt, klb & 121 \\
Operating empty wt, klb & 51 \\
Payload, lb & 1640 \\
Climb time, min & 47 \\
Cruise altitude, kft & $44-51$ \\
Cruise lift-drag ratio & $6.6-7.9$ \\
Block time, hr & 5.9 \\
Block fuel, klb & 61 \\
Reserve fuel, klb & 8 \\
Range, nmi & 4243 \\
\hline \hline
\end{tabular}

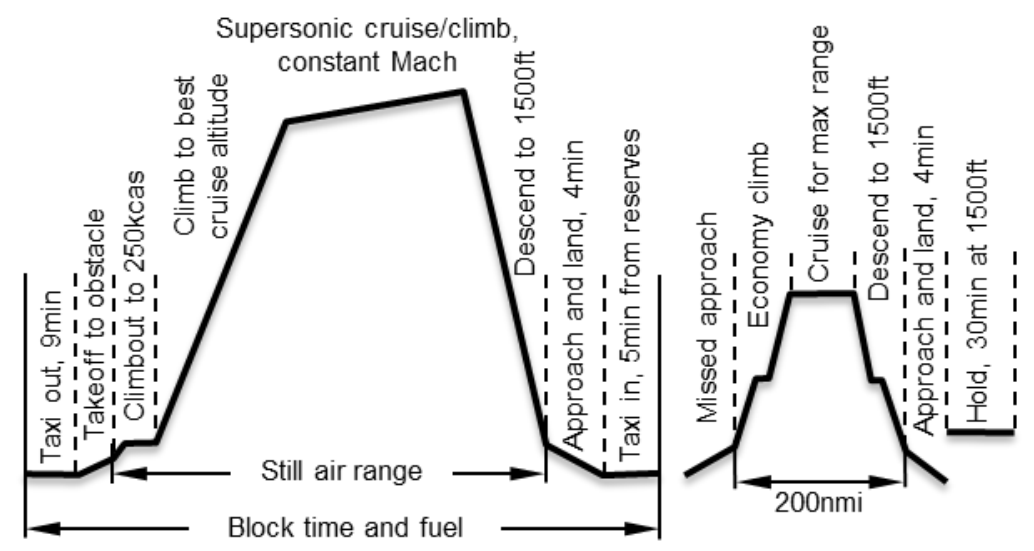

Figure 3. 55t trijet mission profile.

The design mission range of the $55 \mathrm{t}$ trijet is $4243 \mathrm{nmi}$. Performance results are shown in Table 3 . For the CAEP supersonic exploratory study, other missions between specific origin-destination city pairs are being investigated by members of the CAEP evaluation team. These missions will have varying gross weights, ranges, and they may require subsonic cruise segments over any land having supersonic flight restrictions. Methods of providing performance characteristics of the $55 \mathrm{t}$ airplane to AEDT are being investigated by CAEP analysts.

\section{B. Advanced Takeoff Procedures for Noise Certification}

Noise standards and recommended practices for new supersonic civil aircraft do not currently exist. Until new regulations are developed, the brief text relevant to supersonic aircraft in Chapter 12 of [2] states that noise limits given for subsonic aircraft may be used, provisionally, as a guideline. For evaluation purposes, we use subsonic certification procedures to predict noise levels in this report.

Supersonic and subsonic airplanes are anticipated to behave differently in the terminal airspace near airports. The requirement of supersonic flight leads to significant differences in configuration, aerodynamics and propulsion relative to a subsonic aircraft. A supersonic business jet is likely to have a thin wing with a low aspect ratio and a simple flap system. It is likely to require high takeoff speeds before sufficient lift is generated to lift off, and even higher airspeeds to climb with significant thrust margin. Several advanced takeoff procedures have been proposed for supersonic aircraft. Two of these procedures - the high speed climbout and the programmed thrust lapse - promise to reduce certification noise levels, but they may require departures from normal reference procedures defined in noise regulations for subsonic transports. These procedures are investigated in this study.

Normal noise reference procedures for subsonic aircraft require applicants to climb at airspeeds no greater than 20 knots above the takeoff safety speed (this is the "not greater than $V_{2}$ plus $20 \mathrm{kn}$ " requirement defined by 3.6.2(d)(1) of Ref. [2]). It is possible the applicant may want to apply for a departure from this reference procedure to ensure adequate climb performance. Provisions for departures from normal procedures are explained in 3.6.1.4 of Ref. [2]. A departure from normal procedures is allowed if the applicant can show the aircraft performance characteristics demand it and if the certificating authority approves it.

Another possible departure from normal procedures involves engine takeoff power settings. Experience in aircraft sizing analyses suggests that supersonic aircraft are likely to be constrained by a takeoff field length requirement. Therefore, high engine power settings are required during the ground roll and climbout phases of takeoff. But engines capable of supersonic cruise tend to have high specific thrust, high exhaust velocity, and high levels of jet noise, making noise certification a challenging prospect. Reducing jet noise at the lateral measurement condition, where engine power is maximum, is particularly challenging (A sketch showing the arrangement of the noise measurement monitors is shown in Figure 4). Researchers during NASA's Supersonic Cruise Research Program [27] proposed a certification noise reduction procedure to address noise at the lateral condition. This procedure since has become known as the auto-throttle or programmed thrust lapse takeoff [28]. 
As typically envisioned, an advanced takeoff using a programmed thrust lapse begins ordinarily, with maximum thrust applied from brake release through rotation and liftoff. Propulsion noise is highest at maximum thrust, but for observers located laterally across from the aircraft, noise is very efficiently attenuated by ground effects. Lateral attenuation is caused by ground surface absorption, by refraction and scattering effects of the air, and by engine-airframe installation effects. At low elevation angles, these effects can attenuate sound along the lateral sideline by as much as 10dB [29]. The programmed thrust lapse procedure exploits lateral attenuation.

Immediately after the runway obstacle is cleared (but well before the conventional, pilotinitiated throttle cutback takes place), engine thrust is automatically lowered to reduce lateral sideline noise. The programmed thrust lapse is more gradual than the rather abrupt pilot-initiated throttle cutback occurring later. Ideally, the throttle is reduced as the benefit of lateral attenuation vanishes with increasing altitude. Implementation of the programmed thrust lapse (i.e., when it begins, how long it lasts, and how much thrust is allowed to lapse), are under investigation. In this study, it is implemented approximately over the time required for gear retraction and it is completed before the second segment climb begins.

Thus, capitalizing on lateral attenuation via a thrust lapse procedure is a clever idea. Lateral noise is abated, but because takeoff thrust is at maximum through obstacle clearance, takeoff field length does not increase.

However, thrust lapse procedures at low altitude may not be allowed under noise regulations for subsonic transports. Changes to engine power are not permitted by Section 3.6.2(a) of [2]. This requirement defines minimum safe altitudes (689 to 984 feet, depending on the number of engines), below which engine power setting must remain at maximum. Without permission to operate otherwise, regulations rule out part-power takeoffs for noise certification and they would seem to disallow thrust lapse procedures at low altitude. And regulating authorities might be reluctant to approve a pilot-initiated procedure that would increase the workload of the flight crew during takeoff and reduce the rate of climb.

Still, it is thought that a departure from normal reference procedures could be permitted if computer-controlled automatic throttle scheduling is used, making pilot initiation unnecessary. An automatic digital engine control implementation of a programmed thrust lapse could use an airplane's weight-on-wheels sensors, airspeed, altimeter, attitude and air temperature indicators, or perhaps airport navigational aids to begin preprogrammed thrust reduction.

Afterburning during takeoff to shorten field length was used by the Concorde and has been proposed for some future supersonic transports (e.g., [30, 31]). However, unlike the Concorde, use of afterburners would need to be restricted to just the ground roll due to noise concerns. Even so, lateral ground attenuation may be insufficient to abate noise generated on the runway unless the degree of reheat is limited. A programmed thrust lapse would need to consist of a "wet-to-dry" conversion as landing gear is retracted. This would require the nozzle throat to close just after liftoff. No takeoff afterburning is considered in this study.

\section{Takeoff and Approach Analysis}

Thrust requirements for subsonic jet aircraft are most often defined at takeoff conditions, where takeoff field distance is typically an active engine sizing constraint. For supersonic civil aircraft, however, thrust requirements can often be most demanding at top of climb. For many supersonic transports, this leads to an excess of thrust at takeoff conditions. Their engines can often be derated* at takeoff - sometimes substantially - and there may still be sufficient thrust available during climbout to perform a programmed thrust lapse procedure. In this study, engines are assumed to be derated in the terminal airspace only. Above 10,000 feet, engine thrust is not derated and is limited by hot section temperatures.

\footnotetext{
*Derating should not be confused with part-power operation. Derating is a permanent thrust reduction for a given airplane type achieved by programming the engine's digital controller. Derated thrust might be exceeded only if an automatic power reserve system is active in the event another engine becomes inoperative.
}

6 of 19

American Institute of Aeronautics and Astronautics 
For takeoff and approach reference profiles used to predict certification noise, standard acoustic day (ISA $+18^{\circ} \mathrm{F}$ ) conditions are assumed. All performance calculations related to airworthiness [32] use hot day (ISA $\left.+27^{\circ} \mathrm{F}\right)$ conditions. The engines are flat-rated to ISA $+27^{\circ} \mathrm{F}$. Two types of takeoff procedures are considered for the $55 \mathrm{t}$ airplane.

\section{Minimum Field Distance Takeoff}

The first type of takeoff considered is a minimum field distance procedure. It is intended for operations from smaller relief airports popular with business jet operators. Leading edge and trailing edge flap deflections are parametrically varied to minimize takeoff distance for a given amount of engine derate. Engine derate is selected such that the field distance [32] is $7000 \mathrm{ft}$. The minimum takeoff safety speed $\left(\mathrm{V}_{2 \mathrm{~min}}\right)$ is determined by a one-engineinoperative, balanced field calculation. In general, higher flap deflections cause stalling speeds and $V_{2}$ speeds to decrease, and cause takeoff distance to improve. Lift-drag ratio and climb rate performance, however, deteriorate. Leading edge and trailing edge flaps are set to $10 \mathrm{deg}$. and $16 \mathrm{deg}$., respectively, and the engine is derated at low altitudes to 90 percent of its maximum thrust. $V_{2 \min }$ is 177 knots. With tail-mounted engines, the one-engineinoperative yaw drag is small, and as a result the 7000ft field distance is determined by the all-engines-operating 115 percent field distance rather than by the balanced field distance.

\section{Delayed Rotation Takeoff}

When operating from airports having longer runways, takeoffs and climbouts at higher speeds may be preferred. Higher climbout speeds are preferred in general for many supersonic aircraft. The preference for high airspeed can be shown for the 55t STCA by constructing its thrust demand curves. These are shown in Figure 5 for level and steady flight at maximum weight using takeoff flap deflections at an altitude of 2000 feet. The 55t STCA's minimum drag speed $\left(\mathrm{V}_{\mathrm{MD}}\right)$ is nearly 280 knots. This is unlike a subsonic commercial airplane of similar weight in these conditions, which may have a minimum drag speed of perhaps 200 knots. Speeds below the minimum drag speed are in the so-called region

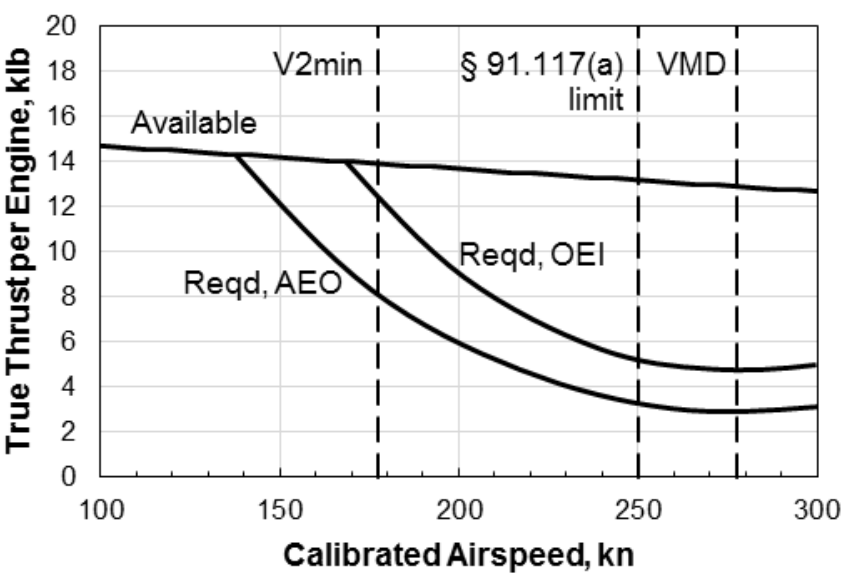

Figure 5. Thrust demand of 55t trijet for level steady flight. of reversed command, where to fly more slowly requires more thrust to overcome increasing lift-dependent drag. Flying safely in this region requires adequate thrust margins, shown in the Figure as the difference between available thrust and required thrust with all engines operating and with one engine inoperative. If a runway is long enough, higher rotation and liftoff speeds would seem to be in order, so that the climbout may take place at a high speed. A delayed rotation is assumed to occur at 195 knots. This results in liftoff speeds of 210 knots for takeoffs with all engines operating. Also noted in the Figure is an airspeed of 250 knots. Unless permission is granted otherwise, flight in excess of 250 knots under 10,000 feet is prohibited in the United States (and in many other countries) by the Code of Federal Regulations 14 CFR § 91.117(a).

Even so, 210 knots is still inside the region of reversed command. This demonstrates the need for delayed rotations and quite possibly an accelerating climbout. Seemingly, an excellent case could be made by supersonic airplane applicants to permit a departure from the climbout speed limit requirement defined by 3.6.2(d)(1) of [2].

For delayed rotation takeoffs, flap deflections are selected not only with field distance and climb rate in mind, but also with noise certification. In ordinary operational practice, flaps are typically retracted on appropriate, sensible schedules during climbout. But per 3.6.2(e) of noise certification procedures [2], applicants are required to maintain position of high-lift devices throughout the takeoff reference profile. Flap deflection influences how much the engine thrust can be cut back per 3.6.2(b) of [2], and therefore is an important factor in noise measured at the flyover monitor. Leading edge and trailing edge flap deflections are selected via a parametric study for a combination of good field performance, climb rate, and low pilot-initiated cutback thrust (6deg. and 10deg., respectively). Takeoff field distance for the 55t STCA using a delayed rotation is $8620 \mathrm{ft}$ from a sea level runway on a hot day.

7 of 19

American Institute of Aeronautics and Astronautics 


\section{Standard Takeoff Procedure}

A takeoff calculation for noise certification from a sea level field is made in accordance with the requirements for subsonic transports in 3.6.2 of [2]. The delayed rotation procedure described above is used. Above the minimum safe altitude, engine power is reduced by a pilot-initiated cutback such that the climb gradient is zero with one engine inoperative, or four percent with all engines operating. The engine power cutback is designed to reduce noise at the flyover monitor. Many certification applicants vary the time and position of the cutback (using an equivalent procedure) to minimize noise slightly at this location. In this study, however, the cutback is complete 18,000 feet from brake release, and the flyover noise is determined entirely by the cutback power noise signature. This takeoff is shown on the left side of Figure 6. This takeoff is permissible without departures from normal procedures for subsonic airplanes defined by 3.6 .2 of [2].
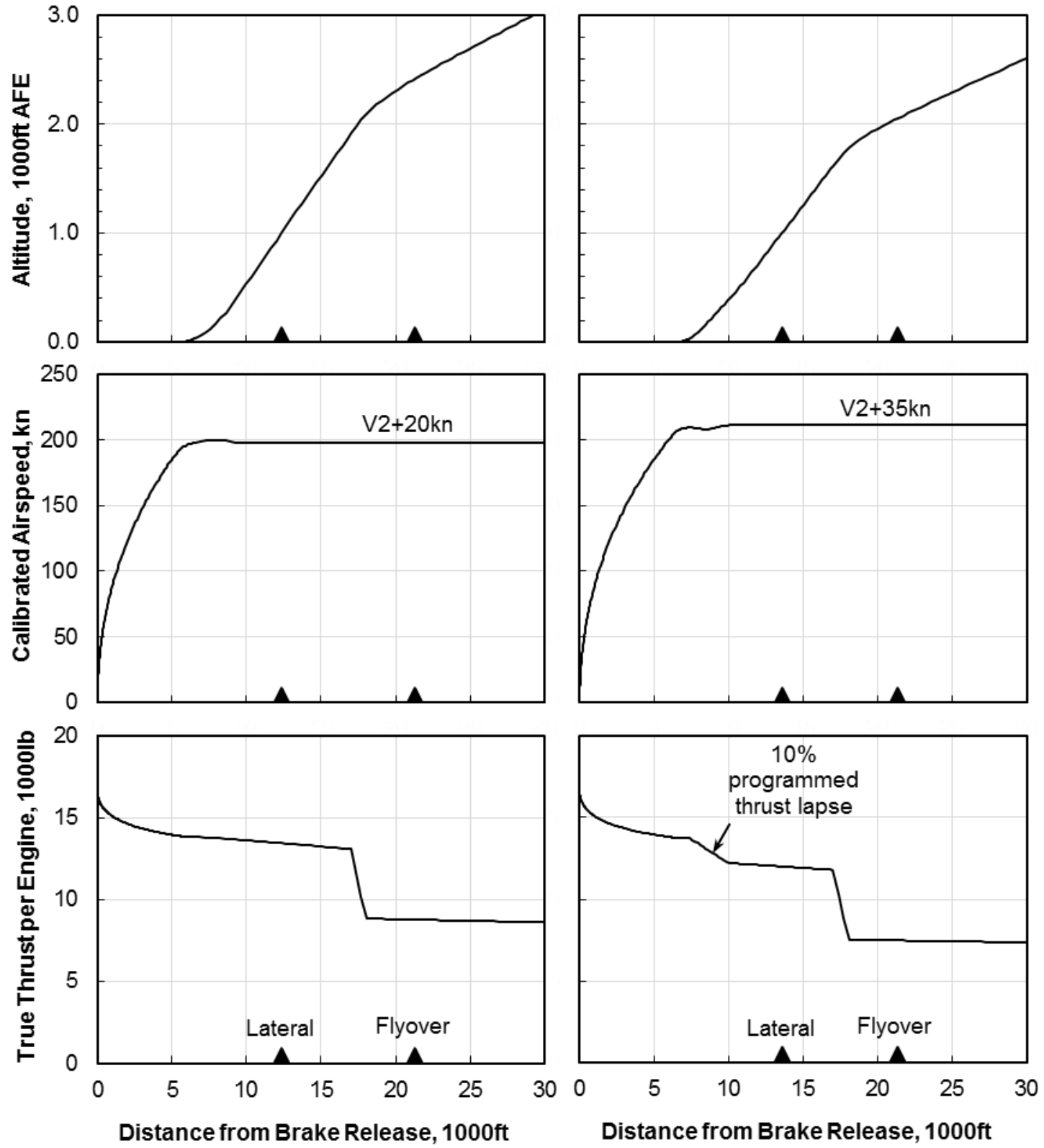

Distance from Brake Release, $1000 \mathrm{ft}$

Distance from Brake Release, $1000 \mathrm{ft}$

Figure 6. 55t trijet profiles for noise analysis: standard takeoff (left, Section III.C.3); advanced takeoff (right, Section III.C.4).

8 of 19

American Institute of Aeronautics and Astronautics 


\section{Advanced Takeoff Procedure}

A noise certification takeoff profile using a programmed thrust lapse rate of ten percent is shown on the right side of Figure 6. Thrust is automatically reduced by digital engine controllers beginning at the runway obstacle. The reduction takes place roughly during the time of gear retraction and is completed by the start of the second segment climb.

Automatic control of engine thrust has been implemented on several popular civil aircraft, albeit not for noise reduction purposes. Regulations governing automatic takeoff thrust control systems were defined under 14 CFR $\S$ 25.904 in 1987. The notion of using programmed thrust lapse as an automatic noise abatement mechanism might be designed as a variable noise reduction system (VNRS) under [33]. Infrequently implemented, a VNRS is a system where noise is abated automatically without flight crew intervention.

Alternately, an examination of the FAA special conditions docket for airplanes having automatic thrust control systems at low altitude is revealing. Digital engine controllers on the Airbus A320 family have an "autothrust" feature that automatically increase thrust with no change in power lever position in the event of a stall [34]. Also, a special condition [35] has been granted to the Embraer 170/190 family in the event of an engine failure, allowing a digital engine controller to automatically increase thrust on the operative engine during a go-around. These examples suggest digitally-automated thrust control procedures such as programmed thrust lapse might be implemented for supersonic aircraft on a case-by-case basis using a special conditions exception. In any event, greater clarity may be helpful if automated thrust control is an enabling noise abatement requirement for supersonic transports.

Satisfying minimum climb gradient requirements may be an important consideration when using a programmed thrust lapse. In the event of an engine failure during climbout, 14 CFR $\S 25.121$ specifies a minimum climb gradient requirement in the segment defined between the points when gear is retracted and an altitude of 400 feet. This regulation requires the remaining operative engines to be at "the power or thrust available when retraction of the landing gear is begun." This, by our assumptions, is the maximum takeoff thrust prior to the programmed thrust lapse. Thus an automatic takeoff thrust control system would be needed to increase thrust on the remaining engines. Further, time to spool the engines up to maximum power must be considered, and so the amount of programmed thrust lapse could be limited. More climb gradient requirements are specified in 14 CFR $\S 25.121$ and in 14 CFR $\S 25.111$.

Additionally, the 55t STCA is assumed to climb out at $\mathrm{V}_{2}+35 \mathrm{kn}$. A higher-speed climbout would require a departure from 3.6.2(d)(1) of [2], with the justification that it may be required to ensure adequate thrust margin and climb performance. Outside of noise certification procedures (that is, in operational practice), early accelerations and high-speed climbouts are sometimes allowed. Permission may be granted on a case-by-case basis if other aircraft are not in the vicinity. In the future, nearby aircraft may need to give more room to supersonic transports. This practice is already common today, where greater spacing intervals are given to large aircraft due to their wake turbulence.

\section{Influence on Noise}

Advanced takeoff procedures have several positive impacts on noise, in addition to reducing lateral noise as noted already. A higher speed climbout at $\mathrm{V}_{2}+35 \mathrm{kn}$ results in less shear between the jet and ambient air, resulting in weaker turbulence and less jet noise. A higher speed climbout also results in generally lower noise due to shorter event duration. Higher airspeed also creates more lift, allowing a deeper pilot-initiated engine thrust cutback. This last effect is noticeable in Figure 6. However, a programmed thrust lapse results in a lower climb rate and a lower altitude over the flyover monitor, thereby increasing noise downrange.

\section{Noise and Emissions}

\section{A. Noise Analysis}

All noise predictions are made using NASA's Aircraft Noise Prediction Program (ANOPP, [36, 37]) using best practices, with predictive methods selected to represent the noise sources of a supersonic business jet as accurately as possible. Jet noise is predicted using an empirical method developed by the Society of Automotive Engineers [38]. For simple, single-stream, round nozzles operating on the cusp of choke, the SAE method is preferred over other available methods based on comparisons of predicted levels to scale model and flight test data [39]. Since jet noise is typically the dominant source in supersonic applications, it is the subject of ongoing study at NASA. A companion paper that documents recent work has been written [40].

Broadband fan noise is predicted using an empirical method developed by General Electric [41], and discrete fan interaction tones are predicted using a similar method [42] (both of these methods are more recent calibrations of ANOPP's original fan noise method). For predicting noise of high-speed, high-pressure-ratio, single-stage fans that might be used in a supersonic application, these methods are preferred based on comparisons made to data collected

9 of 19

American Institute of Aeronautics and Astronautics 
by NASA: the General Electric High Speed Fan [43], the Honeywell Quiet High Speed Fan [44], and a two-stage fan designed and built by Pratt \& Whitney as part of the NASA-led High Speed Research Program. Fan treatment suppression is estimated using a method developed by General Electric [45].

Engine core noise is predicted by a method developed by Emmerling [46]. Engine state data computed by NPSS are fed into ANOPP as functions of flight speed, altitude, and engine power setting.

Landing gear, flap, slat and trailing edge airframe sources are predicted using the empirical Fink method [47]. The predicted levels are adjusted to represent airframe noise levels of a supersonic business jet. These adjustments are based on noise measurements of a supersonic delta-wing transport [48] and are documented in [49].

It should be self-evident that applying empirical methods developed largely for conventional subsonic transports powered by high bypass ratio, separate-flow turbofans to a supersonic delta-wing airplane equipped with a low bypass ratio engine with a supersonic inlet, a long-duct mixer, and a more complex nozzle has a high uncertainty. A Monte Carlo experiment is an attempt to capture these uncertainties. It is discussed in a later section.

Noise levels of all components are predicted as lossless, one-third octave band spectra and are summed in the vicinity of the airplane. The noise sources are analytically flown along the trajectories described in a previous section and are propagated to noise monitors located on the ground. The source levels are computed at half-second intervals using engine state data at the correct flight condition and engine power. This is particularly important in modeling noise during procedures where the engine state is dynamically varying, such as during the proposed programmed thrust lapse procedure. Noise propagation effects include spherical spreading, Doppler shift and convective amplification, atmospheric absorption [50], and ground reflections [51] based on data for grass-covered ground [52]. Noise levels for laterally-displaced observers is evaluated at a position when the airplane is sufficiently high that refraction and scattering effects are small and where lateral attenuation is negligible.

With engines mounted above the vehicle, noise shielding effects must be considered. Shielding (also referred to as barrier attenuation or insertion loss) is an acoustic diffraction phenomenon where sound waves are attenuated when propagated past an impermeable barrier placed between the noise source and an observer. In this study, a simple empirical diffraction model based on optical diffraction theory is used. The model was originally proposed by Maekawa [53] and is reproduced in many foundational acoustic textbooks. Shielding is particularly efficient when the observer is located in the "shadow region" where the noise source is obscured. The delta wing (see Figure 2) provides excellent shielding of forward-radiated fan inlet noise. All other sources are not shielded. Jet noise is a distributed source generated downstream throughout the axial exhaust plume. Core noise is predominantly aft-radiating and is assumed to radiate through the exhaust. Fan exit noise also escapes through the nozzle but it is attenuated by treatment in the bypass duct.

\section{B. Certification Noise Predictions}

Certification noise predictions are made using the noise metric regulated by ICAO [2]: the Effective Perceived Noise Level, or EPNL. Results for the 55t STCA are shown in Figure 7. In both figures, published noise type certificate data of subsonic aircraft are shown. Levels of over 11,000 Chapter 4 aircraft types are plotted against maximum takeoff gross weight. Chapter 3, Chapter 4 and Chapter 14 limits are also plotted in the figures. EPNLs using the standard takeoff procedure (Section III.C.3) are denoted by the open symbols; EPNLs using the advanced takeoff procedure (Section III.C.4) are denoted by the solid symbols.

Lateral EPNLs are predicted to have narrow noise margins. Lateral EPNL is primarily a function of jet noise, without significant influence from other variables. Lateral noise tends to peak wherever the aircraft reaches an altitude of about $1000 \mathrm{ft}$, where ground attenuation effects vanish but before the aircraft gains more altitude. Thus, vehicle aerodynamics play only a small role in lateral noise level. Approach and flyover EPNLs, however, are strongly influenced by vehicle aerodynamics and performance. During takeoff, the engine power setting for the pilot-initiated cutback is determined by climb rate, which in turn is also a strong function of vehicle aerodynamics. Flyover noise margin could erode quickly if the vehicle's performance is overestimated. With the advanced takeoff procedure, the cumulative margin to Chapter 4 is $1.6 \mathrm{EPNdB}$.

10 of 19

American Institute of Aeronautics and Astronautics 

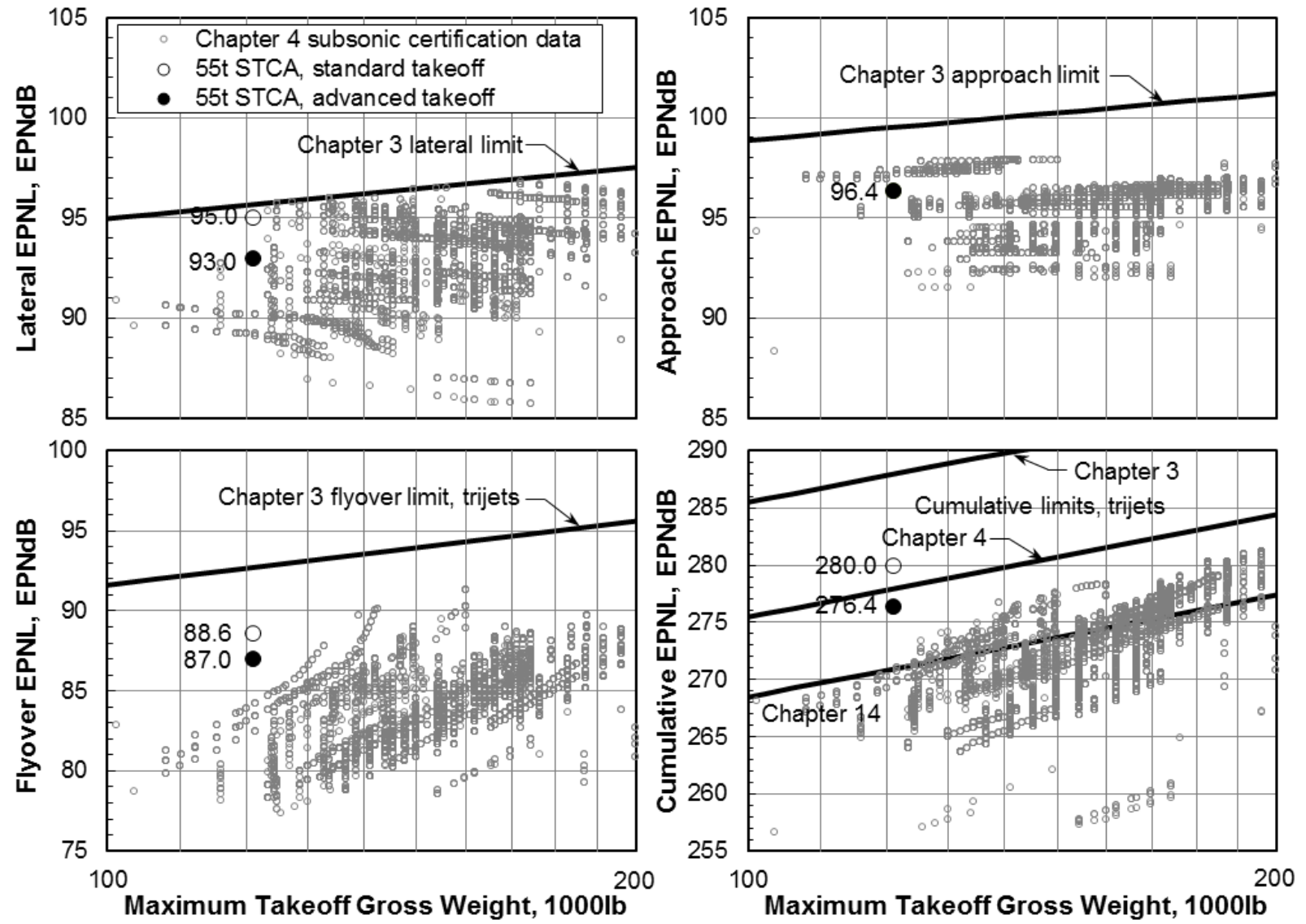

Figure 7. Effective Perceived Noise Level predictions for the 55t trijet.

\section{Noise-Power-Distance Data}

Using the noise prediction methods described above, Noise-Power-Distance values of the 55t STCA are calculated and are provided to CAEP supersonic exploratory study analysts. NPD data are among the inputs required for the ANP database defined in ICAO Doc 9911 [8]. Since ANOPP operates on the one-third octave band paradigm, many noise metrics can be evaluated; including those required by AEDT. ANOPP is used to predict the four types of NPDs used by AEDT: sound exposure level, maximum A-weighted level, maximum tone-corrected perceived noise level, and EPNL. The airplane is flown over an observer at altitudes ranging from $200 \mathrm{ft}$ to $25,000 \mathrm{ft}$ at ten engine power settings. The receiver is located $4 \mathrm{ft}$ above ground level. Ground reflection calculations are enabled. Atmospheric absorption levels [54] required by AEDT are applied to the propagation calculations. The reference airspeed used is currently set to 160 knots, but this logic is under review by members of the CAEP evaluation team. Any and all spectral data (computed natively by ANOPP) are available for use in AEDT. NPDs for the 55t STCA are shown in Figure 8.

\section{Noise Sensitivities}

Because noise results are determined from a variety of methods and input data that are largely uncertain, a Monte Carlo random sampling analysis is performed to provide insight into the system model. Normally deterministic, the benchmark noise model of the $55 \mathrm{t}$ trijet is transformed into a stochastic model by replacing portions of its input data with continuous random values. A vector of input variables representing modeling unknowns is randomly permuted using probability distributions distributed around the model's nominal values. The input variables subject to randomization are chosen by a top-down decomposition of the system noise problem.

11 of 19

American Institute of Aeronautics and Astronautics 

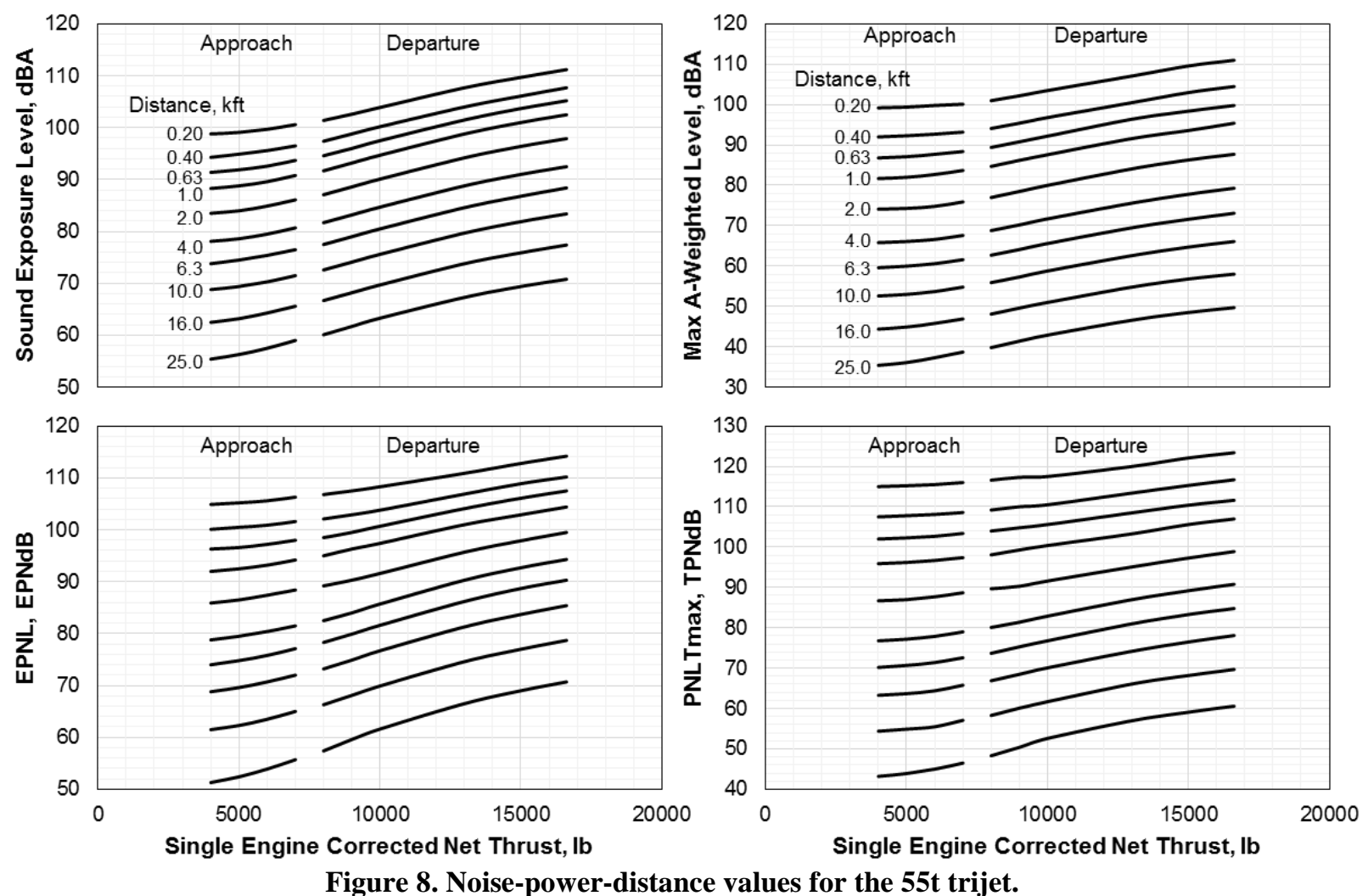

The independent uncertainty variables are chosen to represent various effects that would certainly stray from median values assumed for the benchmark case during the course of aircraft development. Randomly changing variables represent the lack of knowledge of system characteristics, as well as the accuracy of (and uncertainty in) source noise prediction methods. Notably, atmospheric properties are not varied, despite their strong influence on atmospheric absorption and other phenomena. Because ICAO requires acoustic measurements to be corrected to standard acoustic day conditions, there is little reason to include ambient temperature or relative humidity in the experiment. There are no variables assigned to represent variations in wind, terrain, or airport elevation for similar reasons.

Because the airplane is notional, parameters influencing its landing and takeoff profile are subject to variability. Engine power settings on approach and during the pilot-initiated thrust cutback are dependent on airplane weight and aerodynamics. These variables are allowed to change within limits judged reasonable using triangular distribution models. Also, each noise source is allowed to vary by adding or subtracting uncertainties in decibels. In other words, for every random sample in the Monte Carlo experiment, the frequency- and angle-dependent spectra predicted by source noise models are adjusted by simple constants (independent of frequency and emission angle) determined by normal probability distributions. The adjusted sources are summed in the vicinity of the airplane before propagation. Uncertainty in jet noise is guided by experimental and flight test data [39]. Other source noise uncertainties are assigned based on NASA experimental test data and on reviews with industry. Further, ground-specific flow resistance and lateral attenuation are environmental variables affecting noise during certification testing. Last, the wing planform shielding area is allowed to vary uniformly from zero (resulting in no fan inlet noise shielding) to its normal value (resulting in the benchmark shielding predictions). As wing area is varied, wing aspect ratio, taper ratio, and sweep are held constant.

The three certification EPNLs comprise the set of stochastic output response variables. A single analysis requires about three minutes to execute on a contemporary office computer. The Monte Carlo problem lends itself to concurrent parallelization, and so the analysis is multithreaded across several platforms. An automated procedure is easily created to modify a template input file, replace its contents with randomly generated inputs, and run the analysis. The noise model is interrogated 10,000 times. Results of the uncertainty experiment are shown in Figure 9. The sensitivity bars shown in the Figure represent spans of two standard deviations of the EPNL histograms; that is, 95 percent of all samples fall within the bands shown. Statistics for the experiment are shown in Table 4.

12 of 19

American Institute of Aeronautics and Astronautics 

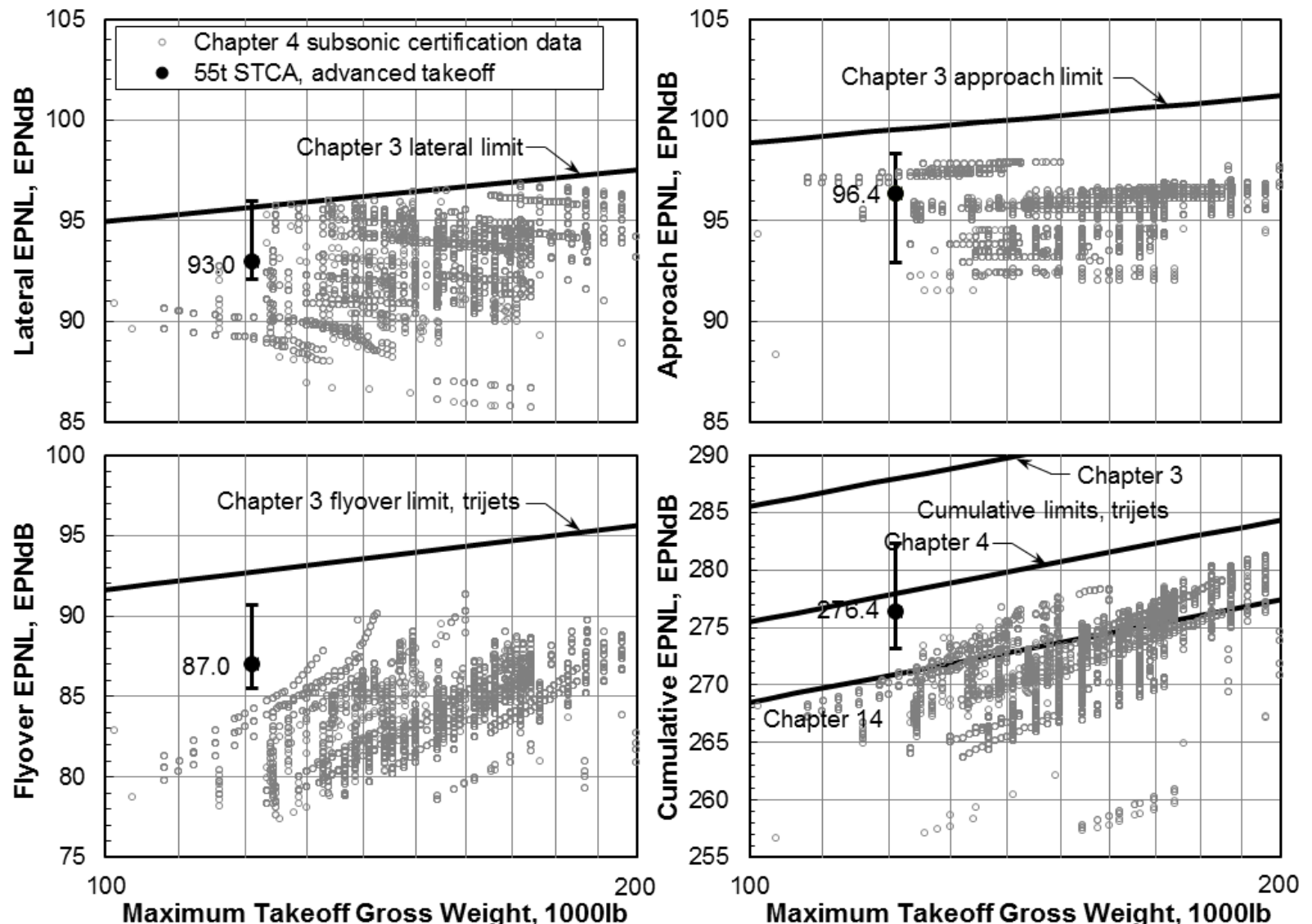

Figure 9. Effective Perceived Noise Level predictions for the $55 \mathrm{t}$ trijet; sensitivity bars represent two standard deviations of Monte Carlo experiment histograms.

After 10,000 samples, there do not appear to be multiple modes or truncations in any of the histograms. Skew and kurtosis are not major factors. A histogram for cumulative EPNL is shown in Figure 10. The histogram and the normal distribution is generated from 10,000 samples and bin span of $0.1 \mathrm{EPNdB}$. As is the case in any uncertainty experiment, the spread of the data perhaps is the most revealing. The standard deviations are on the order of 1 EPNdB at each observer.

\section{E. Landing and Takeoff Characteristic \\ Exhaust Emissions \\ Exhaust emission data are among the inputs} required by AEDT for the CAEP supersonic exploratory study. They are being provided to CAEP analysts in the form of emission indicies, or parts of emittant per thousand parts of fuel burned. The hazardous air pollutants of immediate interest to exploratory study analysts are nitric oxide (NO) and nitrogen dioxide $\left(\mathrm{NO}_{2}\right)$ - collectively known as $\mathrm{NO}_{\mathrm{X}}$ - unburned hydrocarbons (UHC), and carbon monoxide (CO). Emission indicies for these gaseous emittants are designated EINO $_{\mathrm{X}}$, EIUHC and EICO, respectively. Smoke emissions are measured using the smoke number. Emission indicies and the smoke number are used by an

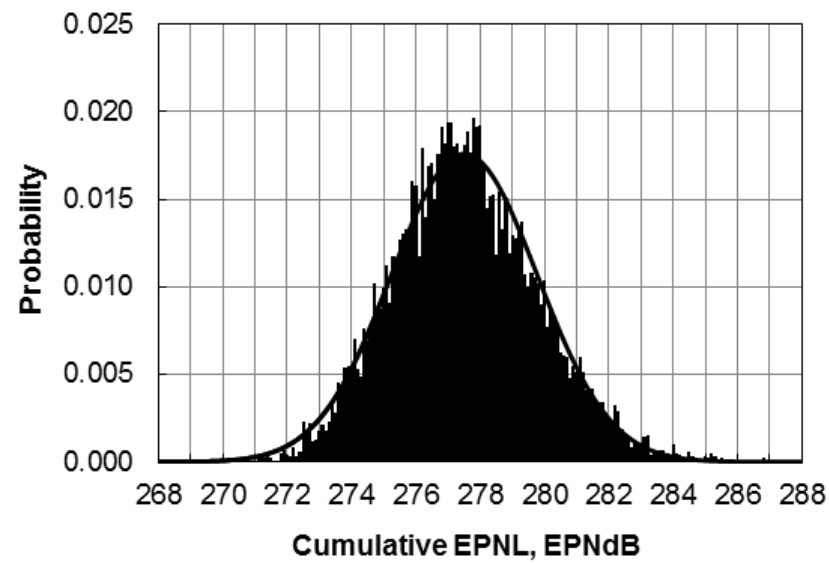

Figure 10. Histogram of cumulative EPNL from the Monte Carlo experiment.

13 of 19

American Institute of Aeronautics and Astronautics 
emission dispersion model within AEDT to compute pollutant concentrations near airports.

The 55t STCA engine is a supersonic variant based on a contemporary, off-the-shelf CFM56-7B core. If emission models of subsonic CFM56-7B series engines can be created, the same emission models can be applied afterwards to the supersonic variant engine (with the tacit assumption that changes made to the low-pressure spool do not influence the behavior of the combustor). Thus, developing emission models of subsonic CFM56-7B series engines first is in order.

Table 4. Sensitivity statistics in EPNdB.

\begin{tabular}{l|c|c|c|c}
\hline \hline Statistic & Approach & Lateral & Flyover & Cumulative \\
\hline \hline Benchmark case & 96.4 & 93.0 & 87.0 & 276.4 \\
Minimum of samples & 91.6 & 90.3 & 83.9 & 270.2 \\
Maximum of samples & 102.6 & 97.5 & 92.9 & 286.8 \\
Range of samples & 11.0 & 7.2 & 9.0 & 16.6 \\
Mean of samples & 95.4 & 94.0 & 88.1 & 277.5 \\
Standard deviation & 1.33 & 0.96 & 1.32 & 2.27 \\
\hline \hline
\end{tabular}

\section{Gaseous Emission Models of the Subsonic Donor Engine}

CFM56-7B series engines have been certified to Annex 16 emission standards. Ground-level emissions data [9] measured at GE Aviation's Peebles test facility for three CFM56-7B series engines* are used to develop regression models for EINO , EIUHC, and EICO. Engines equipped with the Tech Insertion Combustor are the only CFM567B variants still in production. 87 of these particular emission indicies form the basis of the regression models. These indicies are correlated with combustor entrance total temperatures and pressures from the NASA CFM56-7B engine cycle model described earlier.

For $\mathrm{NO}_{\mathrm{x}}$ emissions, a polynomial fit is used to correlate the ratio of $\mathrm{EINO}_{\mathrm{x}}$ and combustor entrance pressure (raised to the 0.4 power) with combustor entrance temperature. For UHC and $\mathrm{CO}$ emissions, power law fits are used to correlate the ratios of EIUHC and EICO and combustor entrance pressure (with no exponent) with combustor entrance temperature. These regressions follow the guidance in reports [3, 55]. The regression models effectively reproduce the ICAO ground level emission index measurements of subsonic CFM56-7B series engines (see Figure 11 , left).

\section{Gaseous Emission Models of the Supersonic Variant Engine}

The same regression models are applied to the supersonic variant engine. Its combustor entrance conditions differ, of course, from the subsonic donor engine. But - if similitude is to be believed - the regression models should respond properly to changes in combustor entrance temperature and pressure, and they should make accurate emission index predictions. Emission index levels of the supersonic engine are plotted against sea level static thrust in Figure 11 (right). Indicated on the Figure are the four thrust settings at which emittants are measured for subsonic engine types (see Section 2.1.4 of [3]). Note that different thrust settings (as well as an additional operating mode) are defined for supersonic engine types by Section 3.1.5 of Annex 16 [3]. Subsonic standards are assumed in this study, though the appropriateness of applying subsonic standards to supersonic engines is under review by ICAO.

Next, the emission models are used to estimate the supersonic variant's characteristic landing and takeoff emittant levels: that is, the emissions metric regulated by ICAO [3]. Predicted index values are multiplied by engine fuel flows and by the times in mode appropriate for subsonic engines. A single engine is assumed tested, and a ten percent development margin is added to all predicted characteristic emission levels.

Using the assumptions noted above, characteristic $\mathrm{NO}_{\mathrm{X}}$ is predicted to be $53.5 \mathrm{~g} / \mathrm{kN}$. Using the rules defined in Annex 16 for subsonic engines, the CAEP/4 regulatory limit is calculated to be $56.4 \mathrm{~g} / \mathrm{kN} .^{\dagger}$ Thus, the $55 \mathrm{t} \mathrm{STCA}$ engine is predicted to qualify for CAEP/4 $\mathrm{NO}_{\mathrm{X}}$ standards. Characteristic $\mathrm{UHC}$ and $\mathrm{CO}$ are predicted to be $14.5 \mathrm{~g} / \mathrm{kN}$ and $135 \mathrm{~g} / \mathrm{kN}$, respectively. Regulatory limits for $\mathrm{UHC}$ and $\mathrm{CO}$ are $19.6 \mathrm{~g} / \mathrm{kN}$ and $118 \mathrm{~g} / \mathrm{kN}$, respectively. The predicted characteristic $\mathrm{CO}$ level exceeds the regulated limit for subsonic engines. Note that the CO standard could be met if the development margin is not needed, if additional engines are tested with repeatable results, or by adjusting the fuel nozzle operation strategy of the combustor's pilot stage and main stage at low engine power.

\footnotetext{
* Engine serial numbers 874-026/01, 778-024/01B and 892-769/01; data collected from 29 September 2005 to 23 March 2006.

$\dagger$ The subsonic CFM56-7B series certifies under the category of engines with maximum rated thrusts greater than $89 \mathrm{kN}$. The supersonic variant, however, falls under that threshold and its limits are calculated differently (see Section 2.3.2 of [3]).
}

14 of 19

American Institute of Aeronautics and Astronautics 

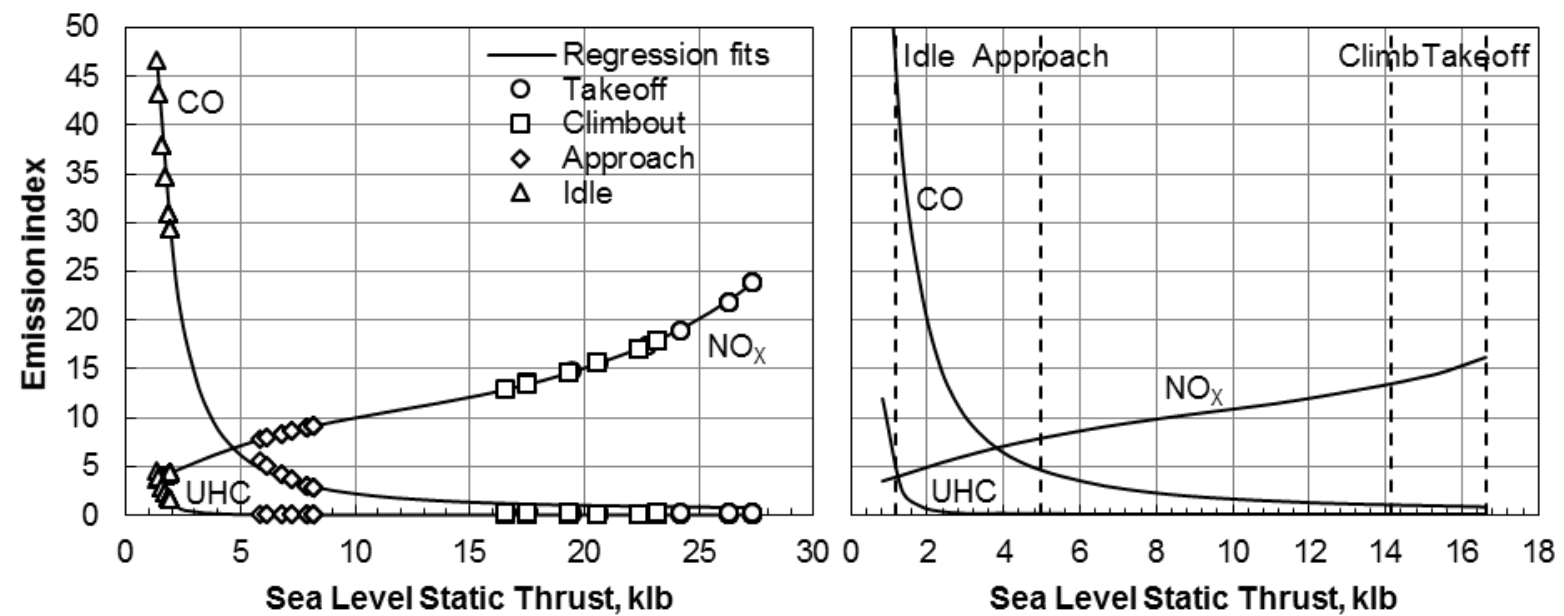

Figure 11. Landing-takeoff gaseous emission index regressions of subsonic CFM56-7B series engines (left); gaseous emission index model of the 55t STCA supersonic variant engine (right).

The ground level emission models are anticipated to be used to predict emissions produced at altitude in AEDT, after additional humidity and engine cycle adjustments [56] are applied. En route emissions during supersonic cruise are of interest to CAEP. The method of applying ground level emission indicies to high-altitude conditions (where combustor entrance conditions would be influenced by supersonic ram effects) is under review by members of the CAEP evaluation team.

Additional models for smoke and non-volatile particulate matter are under development using other modeling processes. They are unavailable in time to appear in this paper.

\section{45 Tonne Supersonic Twinjet Concept}

The $45 t$ concept's airframe is developed by an original equipment manufacturer with an interest in supersonic civil transports. Two NASA-designed engines are mounted aft on short fuselage pylons. Thus, the 45t airplane is a collaborative hybrid, having a company-proprietary airframe, but equipped with NASA engines. To make certification noise predictions, landing and takeoff profiles are computed by the original equipment manufacturer and are provided to NASA for the purposes of this study. Public information for the $45 \mathrm{t}$ airplane is limited to certification noise predictions.

Two supersonic engine variants have been developed from the same engine core model. The first engine variant (described in Section II.A), is the preferred engine for the 55t trijet. For the 45t twinjet, however, the original equipment manufacturer preferred an engine having a higher bypass ratio. A fan with a lower pressure ratio is used, resulting in a higher bypass ratio. Compared with the 55t trijet's engine, this variant has lower jet velocity (eight percent at takeoff), and lower fan tip speed (six percent at takeoff); resulting in a relative noise benefit. Additional characteristics relating to performance of this engine are discussed in the following section.

Unlike the 55t trijet engine, this engine is not derated near sea level. A summary of engine performance data for the engine is shown in Table 5. Ambient conditions above 10,000 feet use International Standard Atmosphere (ISA) conditions, while conditions nearer sea level use hot day (ISA $+27^{\circ} \mathrm{F}$ ) conditions.

Certification noise predictions for the $45 \mathrm{t}$ twinjet are shown in Figure 12. With the advanced takeoff procedure, the cumulative margin to Chapter 4 is $2.6 \mathrm{EPNdB}$.

15 of 19

American Institute of Aeronautics and Astronautics 
Table 5. Performance summary for the $45 t$ twinjet engine.

\begin{tabular}{l|c|c|c}
\hline \hline & $\begin{array}{c}\text { M1.4, 50kft, } \\
\text { ISA }\end{array}$ & $\begin{array}{c}\text { M0.25, sea } \\
\text { level, ISA+27 }\end{array}$ & $\begin{array}{c}\text { Sea level static, } \\
\text { ISA+27 }^{\circ} \mathbf{F}\end{array}$ \\
\hline \hline Net thrust, lb/engine & 3190 & 15,530 & 18,540 \\
Specific fuel consumption, $\mathrm{lb} / \mathrm{hr} / \mathrm{lb}$ & 0.934 & 0.579 & 0.472 \\
Bypass ratio & 3.6 & 3.6 & 3.6 \\
${\text { Burner temperature, }{ }^{\circ} \mathrm{R}}^{\text {Turbine inlet temperature, }{ }^{\circ} \mathrm{R}}$ & 3300 & 3300 & 3300 \\
Compressor exit temperature, $^{\circ} \mathrm{R}$ & 3180 & 3180 & 3180 \\
Overall pressure ratio $^{\text {Fan pressure ratio }}$ & 1430 & 1430 & 1470 \\
Compressor pressure ratio $_{\text {Extraction ratio }}$ & 1.9 & 22 & 22 \\
Nozzle pressure ratio & 11.4 & 1.9 & 1.9 \\
\hline \hline
\end{tabular}
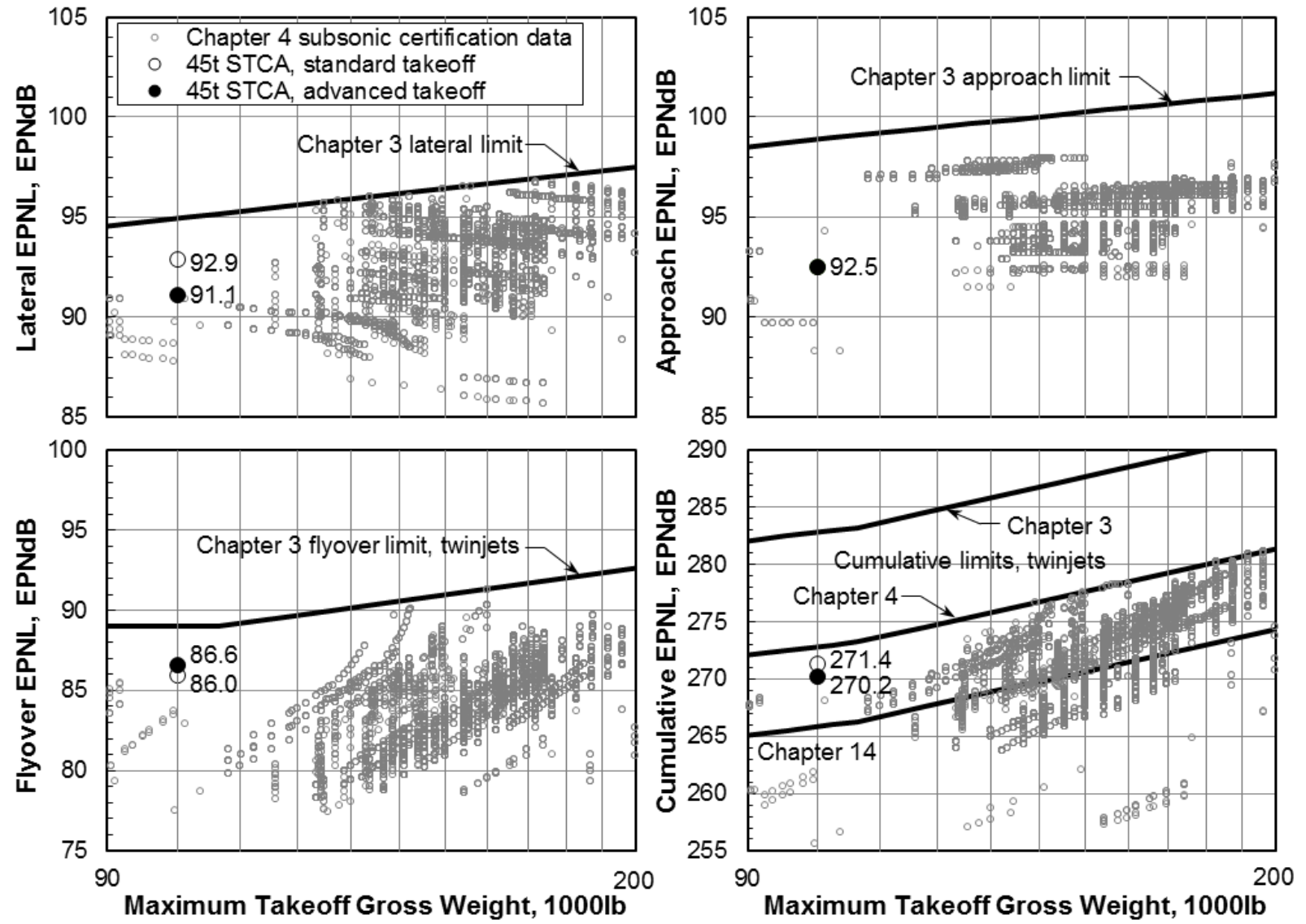

Figure 12. Effective Perceived Noise Level predictions for the $45 t$ twinjet.

\section{Alternative Engine Studies for the $55 t$ Trijet}

At the request of the International Coordinating Council of Aerospace Industries Associations, two alternative engines for the 55t STCA are assessed. The first engine study is an excursion in bypass ratio. The higher bypass ratio variant used for the $45 \mathrm{t}$ twinjet is applied to the 55t trijet. The higher bypass ratio engine has lower specific fuel consumption (compare Table 1 with Table 5). However, it is estimated to be 200lbs heavier, displacing 600lbs of fuel if the 55t maximum gross weight is maintained. Its fan is larger (43.5in vs. $45.5 \mathrm{in}$ diameter), resulting in higher nacelle wetted area, lower nacelle fineness ratio, and higher airplane drag. Thrust at altitude is diminished, resulting in a lower airplane service ceiling. Yet propulsion noise is quieter at all three certification conditions. The cumulative noise benefit is estimated to be 5.3 EPNdB, qualifying the 55t STCA for Chapter 14 (albeit with no margin). However,

16 of 19

American Institute of Aeronautics and Astronautics 
equipped with the higher bypass ratio engine, range decreases from $4243 \mathrm{nmi}$ to $4068 \mathrm{nmi}$; a 4.1 percent penalty. This trade illustrates the preference for engines with high specific thrust for supersonic applications.

The second engine study explores adding a noise reduction technology to the original, lower bypass ratio engine. Nozzle chevrons can be an effective means of reducing jet noise by promoting earlier mixing of the exhaust stream with ambient air, causing a reduction in the jet's overall turbulent kinetic energy. They also introduce a nozzle gross thrust penalty, increasing with the amount of chevron penetration into the exhaust stream. Nozzle chevrons are used in some contemporary subsonic applications, and they could be available for a near-term supersonic application. The cumulative noise benefit of adding chevrons is estimated to be $2.7 \mathrm{EPNdB}$. Chevrons, however, cause range to decrease from $4243 \mathrm{nmi}$ to $4123 \mathrm{nmi}$; a 2.8 percent penalty.

\section{Summary}

A notional 55 tonne supersonic technology concept aeroplane is discussed in this paper. It has been developed and studied by NASA at the request of the FAA and ICAO. The influence that supersonic airplanes will have on operations, fuel consumption, airport noise, and air quality is being assessed by a CAEP exploratory study, with the NASA 55t STCA serving as an analytical proxy for similar early market entrant supersonic airplane types. Being nonproprietary and transparent, the 55t trijet is ideal for use in ICAO's public studies. Aircraft performance, airport-vicinity noise and exhaust emissions are predicted using NASA tools. Using an advanced takeoff procedure, the 55t STCA is predicted to have a Chapter 4 cumulative noise margin of 1.6 EPNdB. Range for a maximum takeoff gross weight mission is $4243 \mathrm{nmi}$. Characteristic exhaust emissions are predicted. Also investigated are some of the anticipated behaviors and requirements of these aircraft in the terminal airspace, the influence of alternative engines, and a lighter, $45 t$ supersonic twinjet.

\section{Acknowledgments}

Thanks to NASA's Commercial Supersonic Technology Project for supporting this study. Thanks also go to the International Coordinating Council of Aerospace Industries Associations, particularly GE Aviation and Gulfstream Aerospace Corporation, for their helpful guidance and suggestions. Thanks go to ICAO's Working Group 1 (Aircraft Noise, Technical) and to Working Group 3 (Aircraft Emissions, Technical), and to the FAA, for including supersonic research into their work programs. Together, they are helping the world understand the impacts of future civil supersonic transports. The vision of viable supersonic transports operating responsibly in an environmentally sustainable manner is a shared pursuit.

\section{References}

[1] Berton, J. J.; Jones, S. M.; Seidel, J. A.; and Huff, D. L., "Noise predictions for a Supersonic Business Jet using Advanced Take-off Procedures," The Aeronautical Journal, Royal Aeronautical Society, Vol. 122 (1250), 2018, pp. 556-571 doi 10.1017/aer.2018.6.

[2] "Annex 16 to the Convention on International Civil Aviation, Vol. I: Aircraft Noise," International Standards and Recommended Practices - Environmental Protection, $7^{\text {th }}$ ed., International Civil Aviation Organization, Montreal, July 2014.

[3] "Annex 16 to the Convention on International Civil Aviation, Vol. II: Aircraft Engine Emissions," International Standards and Recommended Practices - Environmental Protection, $3^{\text {rd }}$ ed., International Civil Aviation Organization, Montreal, July 2008.

[4] U.S. Congress, "FAA Reauthorization Act of 2018, Section 181: FAA Leadership on Civil Supersonic Aircraft," 115 th Congress, $2^{\text {nd }}$ Session, H.R. 302, 3 Jan. 2018.

[5] "Noise Standards: Aircraft Type and Airworthiness Certification," U.S. Code of Federal Regulations, Federal Aviation Advisory Circular 36-4C, 2003, Title 14, Chap. 1, Part 36.

[6] Lee, Cynthia, et. al, “Aviation Environmental Design Tool (AEDT) Technical Manual, Version 3b," Report No. DOTVNTSC-FAA-19-03, Washington, D.C., Federal Aviation Administration, Sept. 2019.

[7] Lee, Cynthia, et. al, “Aviation Environmental Design Tool (AEDT) User Guide, Version 3b," Report No. DOT-VNTSC-FAA19-02, Washington, D.C., Federal Aviation Administration, March 2019.

[8] "Recommended Method for Computing Noise Contours around Airport," Document 9911, International Civil Aviation Organization, Montreal, 2008.

[9] International Civil Aviation Organization (ICAO): “Aircraft Engine Emissions Databank: Ver. 26A, 27 May 2019," European Aviation Safety Agency, Environmental Protection [URL: http://www.easa.europa.eu/environment/edb/introduction.php, retrieved June 3, 2019].

[10] Rizzi, S. A. and Sahai, A. K., "Auralization of air vehicle noise for community noise assessment," CEAS Aeronautical Journal, Vol. 10, No. 1, March 2019, pp 313-334.

17 of 19

American Institute of Aeronautics and Astronautics 
[11] Rizzi, S. A.; Berton, J. J.; and Tuttle, B. C., "Auralization of a Supersonic Business Jet using Advanced Takeoff Procedures," paper to be published, AIAA SciTech Forum and Exposition, 6-10 January, 2020.

[12] Claus, R. W., et al., "Numerical Propulsion System Simulation," Computing Systems in Engineering, Vol. 2, No. 4, 1991, pp. 357-364.

[13] NPSS, Numerical Propulsion System Simulation, Software Package, Ver. 1.6.5, NASA, 2008.

[14] Kirby, M. R.; Mavris, D. N., "The Environmental Design Space," 26th Congress of International Council of the Aeronautical Sciences (ICAS), Anchorage, Alaska, Sep. 14-19, 2008, ICAS 2008-4.7.3.

[15] Suder, K. L., Prahst, P. S., and Thorpe, S. A., "Results of an Advanced Fan Stage Operating Over a Wide Range of Speed and Bypass Ratio, Part 1: Fan Stage Design and Experimental Results,” NASA TM-2011-216769, 2011.

[16] GE Aviation, "GE's Affinity: The first civil supersonic engine in 55 years - launching a new era of efficient supersonic flight," GE press release, 19 Oct. 2018 [URL: https://www.geaviation.com/press-release/business-general-aviation/ges-affinity-firstcivil-supersonic-engine-55-years, retrieved November, 2019].

[17] National Aeronautics and Space Administration, "NASA Awards Contract to Build Quieter Supersonic Aircraft," Press release 18-20, April 2018.

[18] Gloudemans, J.; Davis, P.; and Gelhausen, P., "A Rapid Geometry Modeler for Conceptual Aircraft," AIAA-1996-0052, January, 1996.

[19] Carlson, H. W.; Chu, J.; Ozoroski, L. P.; and McCullers, L. A., "Guide to AERO2S and WINGDES Computer Codes for Prediction and Minimization of Drag Due to Lift," NASA TP-3637, November 1997.

[20] Sommer, S. C. and Short, B. J., "Free-Flight Measurements of Turbulent-Boundary-Layer Skin Friction in the Presence of Severe Aerodynamic Heating at Mach Numbers from 2.8 to 7.0," NACA TN-3391, 1955.

[21] Harris, Roy V., Jr., “An Analysis and Correlation of Aircraft. Wave Drag,” NASA TM X-947, 1964.

[22] Wells, D. P.; Horvath, B. L.; and McCullers, L. A., "The Flight Optimization System Weights Estimation Method,” NASA TM-2017-219627, vol. 1, 2017.

[23] Phoenix Integration, Inc., ModelCenter, Design Integration Software, 1715 Pratt Drive, Suite 2000, Blacksburg, VA 24060, [URL: http://www.phoenix-int.com, retrieved November, 2019].

[24] Geiselhart, K. A.; Ozoroski, L. P.; Fenbert, J. W.; Shields, E. W.; and Wu, L., "Integration of Multifidelity Multidisciplinary Computer Codes for Design and Analysis of Supersonic Aircraft," AIAA Paper 2011-465, 49 ${ }^{\text {th }}$ AIAA Aerospace Sciences Meeting including the New Horizons Forum and Aerospace Exposition, 4 - 7 January 2011, Orlando, Florida.

[25] McCullers, L. A., "Aircraft Configuration Optimization Including Optimized Flight Profiles,” NASA CP-2327, April 1984, pp. 396-412.

[26] Welge, H. R., et al., "N+2 Supersonic Concept Development and Systems Integration,” NASA CR-2010-216842, 2010.

[27] Grantham, W. D., and Smith, P. M., "Development of SCR Aircraft Takeoff and Landing Procedures for Community Noise Abatement and their Impact on Flight Safety," in Supersonic Cruise Research, NASA CP 2108, 1979, pp. 299-333.

[28] Boeing Commercial Airplanes: "High-Speed Civil Transport Study," NASA CR-4233, 1989.

[29] Society of Automotive Engineers: "Method for Predicting Lateral Attenuation of Airplane Noise," Aerospace Information Report 5662, April 2006.

[30] Berton, J. J., et al., "A Comparative Propulsion System Analysis for the High-Speed Civil Transport," NASA TM 2005213414, 2005.

[31] Morgenstern, J., et al., "Advanced Concept Studies for Supersonic Commercial Transports Entering Service in the 2018-2020 Period Phase 2," NASA CR 2015-218719, 2015.

[32] U.S. Code of Federal Regulations, Title 14, Chap. I, Part 25, Airworthiness Standards: Transport Category Airplanes.

[33] "Environmental Technical Manual, Vol. I, Procedures for the Noise Certification of Aircraft," International Civil Aviation Organization (ICAO), Committee on Aviation Environmental Protection, $2^{\text {nd }}$ ed., Document 9501, 2015.

[34] FAA Docket No. NM26; Special Conditions No. 25-ANM-23, "Special Conditions: Airbus Industrie Model A320 Series Airplane," 15 Dec. 1988.

[35] FAA Docket No. NM248; Special Conditions No. 25-241-SC, "Special Conditions: Embraer Model ERJ-170 Series Airplanes; Electronic Flight Control Systems; Automatic Takeoff Thrust Control System," 5 Sept. 2003.

[36] Gillian, R. E., “Aircraft Noise Prediction Program User's Manual,” NASA TM-84486, 1983.

[37] Zorumski, W. E., “Aircraft Noise Prediction Program Theoretical Manual, Parts 1 and 2,” NASA TM-83199, 1982.

[38] Society of Automotive Engineers, "Gas Turbine Jet Exhaust Noise Prediction," Aerospace Recommended Practice 876, March 1978.

[39] Henderson, B. S.; Huff, D. L.; and Berton, J. J., "Jet Noise Prediction Comparisons with Scale Model Tests and Learjet Flyover Data," AIAA Paper 2019-2768, 25 th AIAA/CEAS Aeroacoustics Conference, Delft, Netherlands, 20-23 May, 2019.

[40] Henderson, B. S.; and Huff, D. L., "Scale Model Jet Tests for Learjet Flyover Data," oral presentation, AIAA SciTech Forum and Exposition, 6-10 January, 2020.

[41] Kontos, K. B., Janardan, B., and Gliebe, P. R., "Improved NASA-ANOPP Noise Prediction Computer Code for Advanced Subsonic Propulsion Systems, Volume 1: ANOPP Evaluation and Fan Noise Model Improvement," NASA CR-195480, 1996.

[42] Hough, J. W.; and Weir, D. S., "Aircraft Noise Prediction Program (ANOPP) Fan Noise Prediction for Small Engines," NASA CR-198300, 1996.

[43] Woodward, R. P.; Gazzaniga, J. A.; and Hughes, C. E., "Far-Field Acoustic Characteristics of Multiple Blade-Vane Configurations for a High Tip Speed Fan,” NASA TM-2004-213093, May 2004.

18 of 19

American Institute of Aeronautics and Astronautics 
[44] Weir, D. S., "Design and Test of Fan/Nacelle Models Quiet High-Speed Fan," NASA CR-2003-212370, July 2003.

[45] Kontos, K. B.; Kraft, R. E.; and Gliebe, P. R., "Improved NASA-ANOPP Noise Prediction Computer Code for Advanced Subsonic Propulsion Systems, Volume 2: Fan Suppression Model Development," NASA CR-202309, 1996.

[46] Emmerling, J. J., Kazin, S. B., and Matta, R. K., "Core Engine Noise Control Program. Vol. III, Supplement 1-Prediction Methods," FAA RD-74-125, III-I, March 1976.

[47] Fink, M. R., “Airframe Noise Prediction Method,” FAA RD-77-29, March 1977.

[48] Herkes, W. H.; Stoker, R. W., "Wind Tunnel Measurements of the Airframe Noise of a High-Speed Civil Transport," AIAA Paper A98-16338, 36 ${ }^{\text {th }}$ Aerospace Sciences Meeting and Exhibit, Reno, NV, 12-15 January, 1998.

[49] Rawls, J. W.; and Yeager, J. C., "High Speed Research Noise Prediction Code (HSRNOISE) User's and Theoretical Manual," NASA CR-2004-213014, 2004.

[50] Society of Automotive Engineers, "Standard Values of Atmospheric Absorption as a Function of Temperature and Humidity," Aerospace Recommended Practice 866A, 1975.

[51] Chien, C.; and Soroka, W. W.; "Sound propagation along an impedance plane," J Sound and Vibration, 1975, 43, (1), pp 920.

[52] Embleton, T. F. W.; Piercy, J. E.; and Daigle, G. A.; "Effective flow resistivity of ground surfaces determined by acoustical measurements," J Acoustical Society of America, 1983, 74, (4), pp 1239-1244.

[53] Maekawa, Z., "Noise Reduction By Screens," Memoirs of the Faculty of Engineering, Vol. 12, Kobe Univ., Kobe, Japan, 1966, pp. 472-479.

[54] Society of Automotive Engineers, Committee A-21, Aircraft Noise, "Procedure for the Calculation of Airplane Noise in the Vicinity of Airports," Aerospace Information Report 1845, September 1995.

[55] Madden, P.; Park, K., "Methodology for Predicting NOx Emissions at Altitude Conditions from Ground Level Engine Emissions and Performance Test Information," Rolls Royce, Technical Report No DNS 90713, April 2003.

[56] "Development of the technical basis for a New Emissions Parameter covering the whole AIRcraftoperation: NEPAIR Final Technical Report,”NEPAIR/WP4/WPR/01, EC Contract Number G4RD-CT-2000-00182, 2003.

19 of 19

American Institute of Aeronautics and Astronautics 